\title{
Relationship between Infrared Emissivity and Desert Soil Textures
}

\author{
Bo Qian ${ }^{12}\left(1^{\text {st }}\right)$, Suying Yang ${ }^{12}\left(3^{\text {rd }}\right)$, Zhenhui \\ $\operatorname{Wang}^{12}\left(4^{\text {th }}\right)$ \\ 1 Key Laboratory of Meteorological Disaster of Ministry \\ of Education, Nanjing University of Information Science \\ \& Technology (NUIST) \\ 2 School of Atmospheric Physics, Nanjing University of \\ Information Science \& Technology (NUIST) \\ Nanjing 210044, China
}

\begin{abstract}
Infrared surface emissivity derived from Atmospheric Infrared Sounder (AIRS) is matched with Land Surface Model (LSM) soil texture types to construct a soil emissivity dataset over deserts in northern Africa and the Arabian Peninsula, with which to investigate the relationship between satellite-derived infrared emissivity and desert soil textures. Infrared Desert emissivity spectra from AIRS are compared with the Advanced Space-borne Thermal Emission Reflection Radiometer (ASTER) spectral library. While these data sets differ in their magnitude, the large variability of IR emissivity occurs in several wavelength domains. This variation appears closely related to soil texture and compositions. The highest variation is mostly associated with silicate minerals and particle sizes within the desert soil.
\end{abstract}

Index Terms-Infrared Emissivity, Soil texture, Satellite Remote Sensing

\section{INTRODUCTION}

Land surface emissivity (LSE) is a key parameter which governs the surface energy budget and is also acquired in remote sensing algorithms and data assimilation schemes [1], [2],[3],[4]. At present, the information on LSE in infrared (IR) wavelength is very limited and there is also a lack of accurate IR emissivity model for practical applications. Recently, the infrared measurements from satellite are used to retrieve the surface emissivity over land [4],[5],[6]. Emissivity varies as surfaces variation, depending not only on the amount of land cover and soil moisture, but also on the composition, texture and structure of the underlying soil [7],[8],[9],[10]. LSE is defined as the ratio of thermal radiation emitted by a surface to that of a blackbody, it determines how much thermal radiation is emitted back to the atmosphere and space. The cloud-free radiation at wavenumber $v$ leaving the earth-atmosphere system which can be sensed by a downlooking infrared satellite radiometer including the radiation from the lower atmosphere, the surface, and surface reflectance is given by the expression:

$$
\begin{aligned}
& I_{v}=\varepsilon_{v} B_{v}\left(T_{s}\right) \Gamma(0, Z)+\int_{0}^{Z} B_{v}[T(z)] \frac{\partial \Gamma_{v}(z, Z)}{\partial z} d z \\
& +\left(1-\varepsilon_{v}\right) \Gamma(0, Z) \int_{\infty}^{0} B_{v}[T(z)] \frac{\partial \Gamma_{v}(z, Z)}{\partial z} d z
\end{aligned}
$$

where $I_{v}$ is the observed spectral radiance, $\varepsilon$ is the surface

This work was jointly supported by China's Research and Development Special Fund for Public Welfare Industry (Meteorology GYHY201206002), Nanjing University of Information Science \& Technology(NUIST) science research start project No.20100372 and the Priority Academic Program Development of Jiangsu Higher Education Institutions (PAPD).

\author{
Qifeng $\mathrm{Lu}^{3}\left(2^{\text {nd }}\right.$, Corresponding author) \\ 3 National Satellite Meteorological Center China \\ Meteorological Administration, \\ Beijing 100081, China \\ luqf@cma.gov.cn
}

emissivity, $\Gamma(0, Z)$ is clear sky atmospheric transmittance from zero to sensor altitude $\mathrm{Z}, T_{z}$ is the clear sky atmospheric temperature at altitude $\mathrm{z}, \mathrm{B}(\mathrm{T})$ is Planck's radiation at temperature $\mathrm{T}$. The first term of the equation is the emission from atmosphere of the surface, the second term is the emission from the surface that reaches the sensor, and the third term is downwelling atmospheric emission reflected off the ground under approximation of a lambertian surface. The equation has been applied successfully to observation of infrared radiation at hyperspectral resolution.

Zhou et al. [4] used National Oceanic and Atmospheric Administration (NOAA) regression emissivity product as a first guess for AIRS emissivity retrieval. The largest spectral variation of LSE occurs over barren land such as Northern African desert area and the reststrahlen effect of silicates is main element for strongly spectral variation in the infrared. The regression approach still need to be improved over the desert area. Li et al. [11] developed a physical based algorithm to retrieve the hyperspectral infrared emissivity spectrum simultaneously with the temperature and moisture profiles, as well as the surface skin temperature. Experiment with AIRS radiances shows that simultaneous retrieval of emissivity spectrum and the sounding improves the surface skin temperature and moisture profiles, particularly in the near surface layer. There are molecular vibration band for almost all minerals reflectance and emission spectrum throughout 4 to $25 \mu \mathrm{m}$ [12],[13],[14]. Hanel et al. [15] used the Nimbus-4 infrared interferometer spectrometer(Iris) to measure the infrared spectral to study the surface emissivity properties over globe and found that emissivity features are significantly weakened by the presence of clay horizons, or pedogenic horizons in the soil.

In this paper, infrared surface emissivity derived from Atmospheric Infrared Sounder (AIRS) is matched with Land Surface Model (LSM) soil texture types to construct a soil texture emissivity dataset over deserts in Northern Africa and the Arabian Peninsula, with which to investigate the relations between satellite-derived infrared emissivity and desert soil textures.

\section{EMISSIVITY DATA BASE}

\section{A. Emissivities Derived from Satellite Retrieval}

The Atmospheric Infrared Sounder(AIRS) Launched into Earth-orbit on Aqua Satellite, as part of the NASA Earth 
Observing System on May 4, 2002, is the first of a new generation of high spectral resolution infrared sounders having 2378 channels measuring outgoing radiance between 650$2675 \mathrm{~cm}^{-1}$. AIRS uses cutting-edge infrared technology to create 3-dimensional maps of air and surface temperature, water vapor, and cloud properties. AIRS has a spectral resolution more than 100 times greater than previous IR sounders and provides more accurate information on the vertical profiles of atmospheric temperature and moisture[16]. AIRS Version5 Level 2 support products was employed to build emissivity database in this paper.

\section{B. The ASTER Spectral Library}

The Advanced Spaceborne Thermal Emission Reflection Radiometer (ASTER) on NASA's Terra platform has been widely used in geological and other science studies. As part of the ASTER activities, a library of over 2000 spectra of natural and man-made materials was compiled as the ASTER Spectral Library. The library includes spectra of rocks, minerals, lunar soils, terrestrial soils, manmade materials, meteorites, vegetation, snow and ice covering the visible through thermal infrared wavelength region $(0.4-15.4 \mu \mathrm{m})$ [17].We use the ASTER spectral library V2.0 for surface properties study.

\section{RELATIONSHIP BETWEEN EMISSIVITY WITH SOIL TEXTURES}

\section{A. Study Area}

From the AIRS retrieval, the magnitude of LSE variability requires us to have more investigation in arid and semiarid desert region. While most of thess region is covered by sand and gravel. Hammadas also make up a large part of the desert. Therefore, it is necessary to investigate the land surface soil composition due to its significant influences to emissivity. In this paper, northern Africa and the Arabian Peninsula region ($20^{\circ} \mathrm{E}-60^{\circ} \mathrm{E}, 0^{\circ} \mathrm{N}-40^{\circ} \mathrm{N}$ ) was chosen as study area .

\section{B. Noah Land Surface Model (LSM) Soil Texture Types Database}

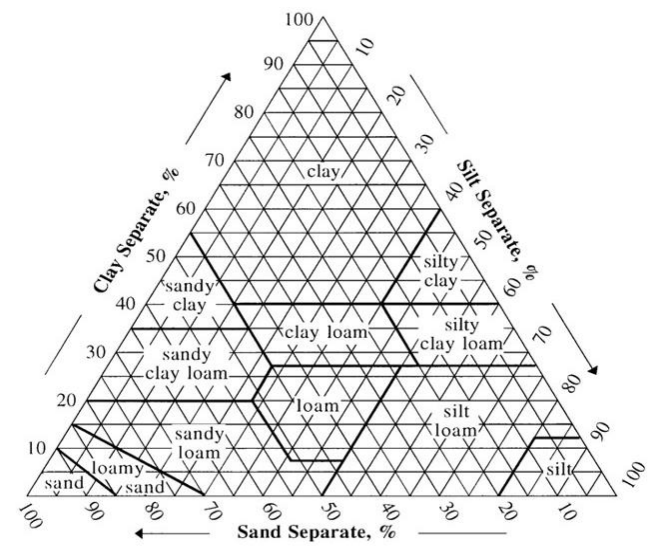

Fig. 1. Soil texture class in the U.S. texture triangle

Noah LSM soil texture database includes 19 soil texture types with $20 \mathrm{~km}$ resolution is used in NCEP operational regional models and it is based on Zobler's assessment of Food and Agriculture Organization (FAO) dominant soil units and soil texture classes. Dot grid overlay was used to determine the largest map unit of each one-degree cell[18]. The database is suitable for large-area studies such as climate research with Global Climate Models (GCMs), or small-scale studies in soils, agriculture, forestry and hydrology[19].

Figure 1 shows soil texture classification which is based on the soil texture triangle. All soil texture types are defined by different fraction of sand, silt and clay. From Fig. 1, we can get

a) sand, loamy sand, sandy loam and sandy clay loam are with sand-rich types, the fraction of sand is above $50 \%$, and for fraction of sand, sand is maximum, loamy sand is medium and sandy loam is minimum;

b) clay, silt clay are with clay-rich types, the fraction of clay is above $50 \%$;

c) silt, silt loam and most of silty clay loam are with silt-rich types, the fraction of silt is above $50 \%$. At mean while, sandy clay is with high sand(45\%-65\%) and clay(35\%$55 \%$ ) percent , and low clay(under $20 \%$ ) percent, clay loam is with sand $(20 \%-45 \%)$ and clay $(27 \%-40 \%)$, and silt (15\%-50\%).

As we know, the main minerals in sand is quartz and it is composed of $\mathrm{SiO}_{2}$, so we defined sand, loamy sand, sandy loam and sandy clay loam are quartz-rich soil texture types.

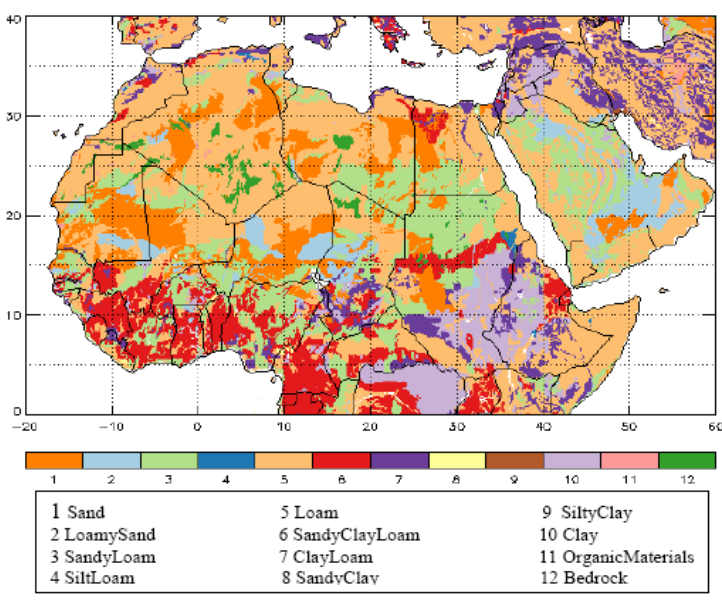

Fig. 2. Map of 12 Soil types in Northern Africa regions derived from the Noah LSM soil texture database

Figure 2 shows the geographic distribution of existing 12 soil texture types in northern Africa and the Arabian Peninsula regions derived from the Noah LSM soil texture database and we can see clearly latitude and longitude distribution of every soil texture type.

\section{Desert Soil Texture Emissivity Database}

AIRS Version5 Level 2 support products 91 days data throughout Jan. to Mar. in 2008 are selected for building infrared land surface soil emissivity datasets over northern Africa and the Arabian Peninsula regions. An AIRS emissivity dataset from 3.7 to 15.4 micrometers is derived from cloudclearing data quality control by setting cloud clearing indicator[16]. Afterwards, we get the 12 soil texture emissivity spectrums dataset by matching AIRS retrieval emissivity dataset with Noah LSM soil texture database. 


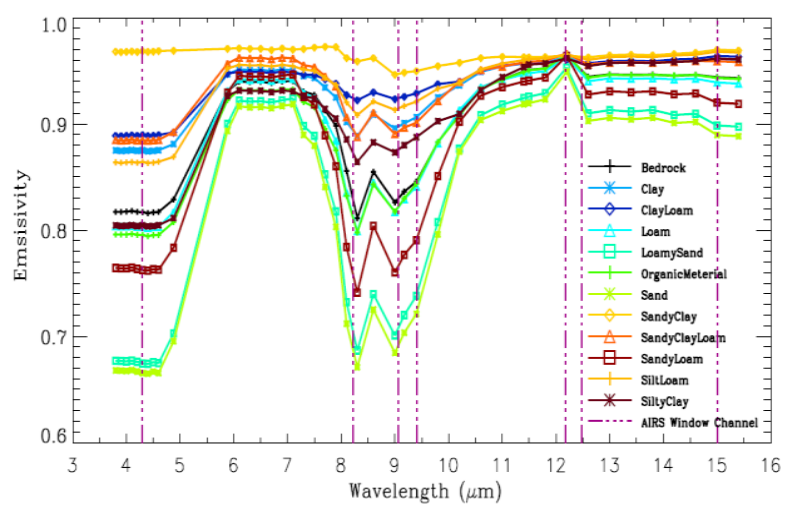

3. Land emissivity spectra including 12 soil texture types over Northern Africa and the Arabian Peninsula throughout Jan. to Mar. 2008

As indicated in Fig. 3 that AIRS emissivity spectrums can obviously distinguish different soil texture types distribution over study areas at $4.3,8.3,8.6 \mu \mathrm{m}$ and $9.17 \mu \mathrm{m}$ which are nearby the AIRS window channels 8.22, 9.07 and $9.40 \mu \mathrm{m}$. The emissivity spectrum at 12.2 and $14.99 \mu \mathrm{m}$ has weak ability in distinguishing soil types. Moreover, at the AIRS window channels $8.22,9.07$ and $9.40 \mu \mathrm{m}$ emissivity values of sand, loamy sand and sandy loam increase in sequence, and the sand contents of these three sand-rich soil texture types decrease in sequence. As sand-rich soil texture type, for example sandy clay, is with maximum emissivity value at the AIRS window channels partly due to its geographic distribution is out of desert regions, we can find this interesting phenomenon from the map of soil texture types in northern Africa and the Arabian Peninsula . Because the latitude ranges of Sahara desert is mainly located between $15^{\circ}$ and $30^{\circ}$, so we think the emissivity spectrum of sandy clay is not dominated by abundant sand, at mean time it represents weak spectrum response characteristic at AIRS window channels.

\section{MinERALOGY ANALYSIS AND RESPONSE CHARACTERISTICS WITH SPECTRAL PROPERTIES OF SOILS AND MINERALS BASED ON LABORATORY MEASUREMENTS}

Ground-based and laboratory measurements of natural materials have the distinct advantage of providing high spectral resolution emissivity information with continuous coverage throughout thermal infrared spectra. The main disadvantage of these laboratory measurements is the inability to accurately represent the mixing of pure scene types and the "canopy" effects of vegetation and surface roughness. For the desert surface, due to its plainness and lack of the vegetation the disadvantage can be ignored.

\section{A. Carbonate Mineral Samples}

Four carbonate mineral samples including aragonite, calcite, cerussite and dolomite from ASTER Spectral Library are selected for producing emissivity spectrum. These carbonates emissivity spectra are presented in Fig. 4, and show rather weak emissivity spectral signatures and no any spectral response characteristics in the AIRS window channels.

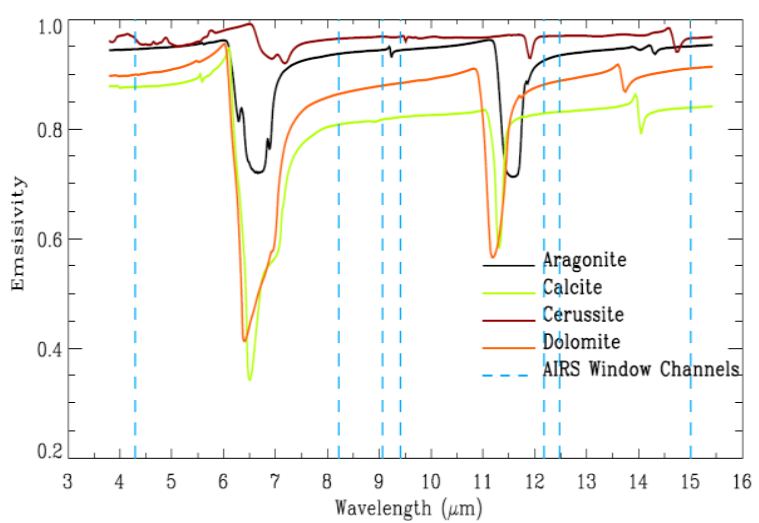

Fig.4. Emissivity values for earth surface carbonates derived from ASTER/JHU spectral library

\section{B. Silicate Mineral Samples}

Three silicate mineral samples including one coarse quartz, one fine quartz and one solid quartz samples from ASTER Spectral Library are selected for producing emissivity spectrum. The particle sizes of fine quartz and coarse quartz are $0-74 \mu \mathrm{m}$ and $75-250 \mu \mathrm{m}$, respectively. These quartz emissivity spectrums are presented in Fig. 5, and these spectra are dominated primarily by $\mathrm{Si}-\mathrm{O}$ stretching reststrahlen bands of quartz mineral [8], show very strong emissivity spectral signatures in some AIRS window channels.

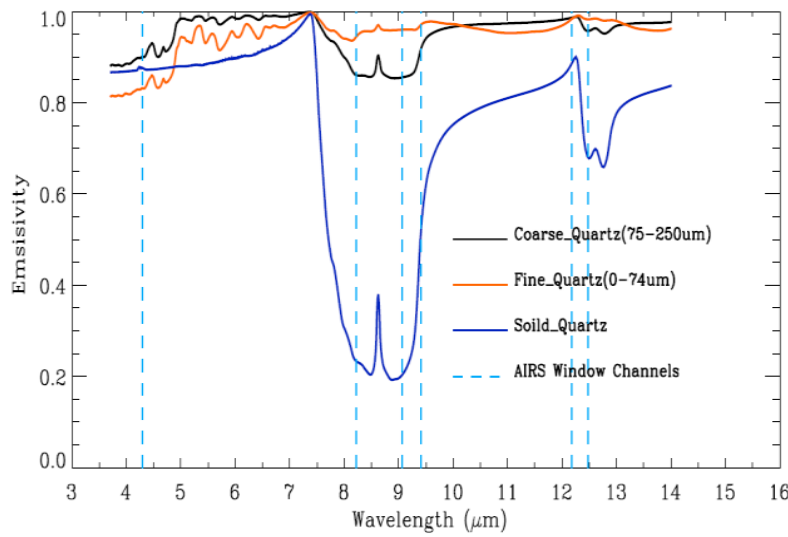

Fig. 5. Quartz emissivity values for different particle size derived from ASTER/JHU spectral library

As presented in Fig. 5, emissivity spectra of fine quartz at the AIRS window channels 8.22, 9.07 and $9.40 \mu \mathrm{m}$ is larger than coarse quartz due to its smaller particle size, and they have relative weak quartz reststrahlen doublet compared to solid quartz that derived from land fracture surface with clear and transparent fragment of single crystals.

\section{Response Characteristics with spectral properties of Soil and Mineral}

Desert soil texture emissivity database derived from AIRS emissivity retrieval and Noah LSM soil texture database, see Fig. 3, provides us with clear multiple soil texture emissivity spectra throughout infrared broadband. These emissivity spectra typically are dominated by quartz reststrahlen bands, including the strong symmetric stretching vibration fundamentals between $8 \mu \mathrm{m}$ and $10 \mu \mathrm{m}$ and the weaker asymmetric stretching fundamentals between 12.2 and $13 \mu \mathrm{m}$. 
Quartz plays a major role to drive these soil emissivity spectrums and it leads directly to sand-rich soil types with smaller emissivity values and visible reststrahlen bands at some AIRS window channels. For clay-rich and silt-rich soil textures, weak reststrahlen bands of quartz are greatly broadened with no visible absorption doublet due to their abundant clay and silt content, this is the reason why they have higher emissivity values.

From Fig. 4 and Fig. 5, we can see carbonates samples show rather weak spectral signatures and silicates samples have a very strong spectral signatures in some AIRS window channels. The main emissivity doublet of quartz for library spectra centered around $8.6 \mu \mathrm{m}$ is clearly visible together with the secondary doublet around $12.2 \mu \mathrm{m}$. Compared Fig. 3 with Fig. 5, spectral response characteristics of satellite-derived emissivity and in-situ derived emissivity from JPL laboratory measurement shows a good visual agreement on the long wavelength side of the main quartz doublet which is important for characterizing certain surface materials, particularly quartz in sandy soils, but on the short-wavelength side of the main quartz doublet especially near $4.3 \mu \mathrm{m}$, satellite-derived emissivity does not capture the variation of the emissivity spectral response characteristics and the quality of the AIRS emissivity products still is an active area of ongoing validation and refinement. Meanwhile, the spectral response characteristics of JPL mineral emissivity spectrum and satellite retrieved emissivity provide us an opportunity to understand mineral composition of desert soils.

\section{CONCLUSION}

A desert soil texture infrared emissivity database based on soil taxonomy was developed by matching AIRS V5 surface emissivity products with Noah LSM soil texture database and were compared with soil minerals spectrum from ASTER spectral laboratory measurements. It was shown that strong signatures and good consistency of infrared emissivity spectral response with earth surface material properties at some AIRS window channels. Large variability of IR soil emissivity over deserts is intimately related to a wide variety of texture, and high sensitivity of emissivity is due to the variety of silicates mineral composition of desert soils and particle sizes. For better understanding the physical interpretation of the satellite signals, more systematic comparisons with thermal infrared measurement still need to be investigated in future.

\section{ACKNOWLEDGMENT}

Authors would like to thank Dr. Fuzhong Weng and Dr. Banghua Yan from NOAA/NESDIS for kindly providing their advice for this study and also thank NOAA/NCEP for sharing Noah LSM soil texture database for surface properties study. We are grateful to Jet Propulsion Laboratory from the California Institute of Technology for making accessible the ASTER Spectral Library.

\section{REFERENCES}

[1] Kenta Ogawa, T. S. (2004). "Mapping Surface Broadband Emissivity of the Sahara Desert Using ASTER and MODIS Data."[J]. Earth Interactions 8(No.7): 1-14.
[2] Bonan, G. B., et al., The land surface climatology of the NCAR community land model coupled to the NCAR Community Climate Model, [J]. J. Climate, 15, 3123-3149, 2002.

[3] Dickinson, R. E., et al., Biosphere-Atmosphere Transfer Scheme (BATS) Version le as coupled to the NCAR Community Model, [R]. NCAR Tech.Note, NCAR/TN387+STR, 72 pp., Natl. Cent. Atmos. Res., Boulder, CO, 1993.

[4] L. Zhou, M. Goldberg., C. Barnet, et al , "Regression of Surface Spectral Emissivity From Hyperspectral Instruments," [J]. IEEE Trans. Geosci. Remote Sens. vol. 46,no. 2,pp. 328333,Feb,2008.

[5] Jun Li, J. L., Elisabeth Weisz, and Daniel K. Zhou, "Physical retrieval of surface emissivity spectrum from hyperspectral infrared radiances." [J]. Geophys. Res. Lett.vol, 34: L16812. 2007

[6] S. W. Seemann, E. E. B., R. O. Knuteson, G. R. Stephenson, and H-L. Huang. "Development of a Global Infrared Land Surface Emissivity Database for Application to Clear sky sounding retrievals from multispectral satellite radiance measurements" [J]. J. of App. Meteo. and Clima. Vol. 47,: 108123.

[7] C. Prabhakara, G. Dalu, "Remote Sensing of the Surface Emissivity at $9 \mu \mathrm{m}$ Over the Globe", J. Geophys. Res. vol. 81,no. 21,pp. 3719,Jul. 20, 1976

[8] J. W. Salisburg, D. M. D. A., "Emissivity of Terrestrial Materials in the 8-14 um Atmospheric Window," [J]. Remote Sens. Environ. no.42,pp. 83-106,July.,1992

[9] Wilber, A. C., D. P. Kratz, and S. K. Gupta, Surface emissivity maps for use in satellite retrievals of longwave radiation, [R]. NASA/TP-1999-209362, pp. 30, NASA, Greenbelt, Md., 1999.

[10] K. Ogawa, T. S., F. Jacob, and A. French, "Estimation of land surface window (8-12 um) emissivity from multispectral thermal infrared remote sensing - A case study in part of Sahara Desert ," [J]. Geophys. Res. Lett., vol. 30,no. 2,pp. 1067,2003.

[11] Jun Li, J. L., Elisabeth Weisz, and Daniel K. Zhou , "Physical retrieval of surface emissivity spectrum from hyperspectral infrared radiances." Geophys. Res. Lett.vol, 34: L16812. 2007

[12] Lyon, R. J. P. , "Evaluation of Infrared spectrophotometry for compositional analysis of lunar and planetary soils" [R].NASA Tech. Note TND-1871, 1963

[13] Hovis, W. A., and W. R. Callahan, Infrared reflectance of igneous rocks, tuffs, and red sandstone from 0.5 to 22 microns [J]. J . Opt. Soc. Amer., 56, 639-643, 1966.

[14] Hunt,G . R., and J.W. Salisbury , Mid-infrared spectral behavior of igneous rocks, [M]. Environ. Res. Pap. 496, 142 pp., Air Force Cambridge Res. Lab., Bedford, Mass., 1974.

[15] R. A. Hanel, B. J. Conrath, V. G. Kunde, et al, "The Nimbus4 Infared spectroscopy experiment I ,Calibrated thermal emission spectra " [J].J. Geophys. Res. vol. 77 ,pp. 2629-2641,1972.

[16] M. T. Chahine, H. A., M. Goldberg, L. McMillin, et al, "AIRSTeam Retrival For Core Products and Geophysical Parameters,"[R]. AIRS Level 2 Algorithm Theoretical Basis Document Version 2.2,2001

[17] A.M. Baldridge, S. J. H., C.I. Grove, G.Rivera (2009). "The ASTER spectral library version 2.0," [J].Remote Sensing of Environment (113): 711-715.

[18] L. Zobler, "A World Soil File for Global Climate Modelling," NASA Technical Memorandum 87802, NASA Goddard Institute for Space Studies, New York,U.S.A.,1986.

[19] B. Staub, C. Rosenzweig, "Global Digital Data Sets of Soil Type, Soil Texture, Surface Slope and Other Properties: Documentation of Archived Data Tape", NASA technical memorandum \#100685,NASA Goddard Space Flight Center Institute for Space Studies,2880 Broadway, New York, NY 10025, Oct. 1987. 